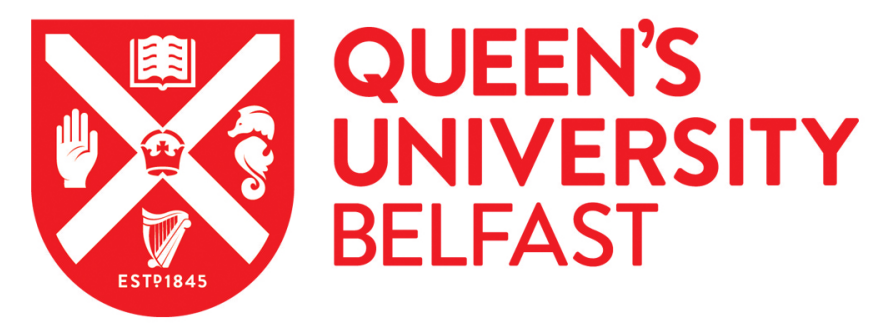

\title{
Large Eddy Simulation on Combustion Noise in a Non-premixed Turbulent Free Flame: Effect of Oxygen Enhancement
}

Ehsanierakhshan, F., Mazaheri, K., \& Mahmoudi, Y. (2020). Large Eddy Simulation on Combustion Noise in a Non-premixed Turbulent Free Flame: Effect of Oxygen Enhancement: Effect of oxygen enhancement. Energy, 210, [118534]. https://doi.org/10.1016/j.energy.2020.118534, https://doi.org/10.1016/j.energy.2020.118534

\section{Published in:}

Energy

\section{Document Version:}

Peer reviewed version

Queen's University Belfast - Research Portal:

Link to publication record in Queen's University Belfast Research Portal

\section{Publisher rights}

(C) 2018 Elsevier Ltd. All rights reserved.

This manuscript is distributed under a Creative Commons Attribution-NonCommercial-NoDerivs License

(https://creativecommons.org/licenses/by-nc-nd/4.0/), which permits distribution and reproduction for non-commercial purposes, provided the author and source are cited.

\section{General rights}

Copyright for the publications made accessible via the Queen's University Belfast Research Portal is retained by the author(s) and / or other copyright owners and it is a condition of accessing these publications that users recognise and abide by the legal requirements associated with these rights.

Take down policy

The Research Portal is Queen's institutional repository that provides access to Queen's research output. Every effort has been made to ensure that content in the Research Portal does not infringe any person's rights, or applicable UK laws. If you discover content in the Research Portal that you believe breaches copyright or violates any law, please contact openaccess@qub.ac.uk. 


\title{
Large Eddy Simulation on Combustion Noise in a Non- premixed Turbulent Free Flame: Effect of Oxygen Enhancement
}

\author{
Faeze Ehsanierakhshan $^{\mathrm{a}}$, Kiumars Mazaheri ${ }^{\mathrm{b}, 1}$, Yasser Mahmoudi $^{\mathrm{c}}$ \\ a Tarbiat Modares University, Tehran, 14115-111, Iran, PhD candidate, Mechanical Engineering Department, \\ f.ehsaniderakhshan@modares.ac.ir. \\ b Tarbiat Modares University, Tehran, 14115-111, Iran, Professor, Mechanical Engineering Department, \\ kiumars@modares.ac.ir. \\ ${ }^{c}$ Queen's University Belfast, BT7 1NN, UK, Lecturer, School of Mechanical and Aerospace Engineering, \\ s.mahmoudilarimi@qub.ac.uk
}

\begin{abstract}
Present work examines the effect of a low-level oxygen concentration enhancement in the oxidizer stream, on the generation of direct combustion noise in a non-premixed turbulent free flame. A hybrid approach utilizing a large eddy simulation, partially stirred reactor combustion model, and Lighthill analogy was employed to predict the sound pressure level in the farfield of the flame. Contributions of different noise sources, including heat release rate and, mole consumption and production rate fluctuations are calculated to predict the sound pressure level in the farfield. Results show that, in comparison to the flame burning with air, the higher temperature in oxygen enhanced flame leads to an increase in the heat release rate and an increase in the rate of consumption and production of the species. The total sound pressure level found to increase by adding oxygen to the oxidizer stream, especially in low frequency ranges. Enhancement of molar oxygen by $10 \%$, increases the noise contribution of the heat release rate fluctuations about $20 \mathrm{~dB}$ in low frequency range, and about $10 \mathrm{~dB}$ in high frequencies. Additionally, the noise contribution from the mole consumption and production rate decreases about $5 \mathrm{~dB}$ in low frequency range and $10 \mathrm{~dB}$ in high frequencies. Keywords: Combustion Noise, Oxygen Enhanced Combustion, Large Eddy Simulation, Computational Fluid Dynamics, Partially Stirred Reactor.
\end{abstract}

\footnotetext{
${ }^{1}$ Corresponding author. Tel.: +98 (21) 82883352
} 


\section{Introduction}

Oxygen-enhanced combustion (OEC) refers to a kind of combustion in which higher concentration of oxygen is used in the oxidizer stream rather than regular air. It has been shown that OEC provides an opportunity to improve combustion process in combustion systems. For example, Schluckner et al. have shown with a CFD model that OEC can be utilized efficiently in reheating furnaces to minimize material losses, increase productivity and efficiency and reduce costs [1]. Other works have showed significant results including reduction in the fuel consumption in a metal reheating furnace with a 5\% excess of oxygen in air stream [2], increasing heating rate by $53.6 \%$ with $30 \%$ oxygen enriched air in a test furnace [3], a higher temperature and thermal efficiency in a gas turbines [4], improvement of thermal efficiency and more complete combustion in a waste-to-energy plant[5] and other industrial equipment that involve combustion [6].

OEC has been used in a broad range of industrial applications such as metals, glass, coal-fired power plants and incineration. Generally actual total energy saving depends on different parameters such as the oxygen required flow and purity need, reduction both in the raw materials and in the volume of the exhaust gases, productivity of the OEC systems, and value of the byproducts of oxygen production plants (argon and nitrogen). But raised fuel price and needs for fuel saving, stricter environmental laws and recent advances in oxygen generation, have made OEC an economical way to enhance combustion efficiency and reduce fuel consumption and it is anticipated to be a central combustion technology in the near future [6].

One major issue in this technology is the combustion noise associated with the OEC systems. While numerous theoretical and experimental works on air-burning flame combustion noise exist in the literature from 1960s [7], research on the OEC noise emission has received little attention. However, some experimental studies which are dedicated to emitted noise level measurement in high-level OEC systems (with >90\% oxygen by volume in oxidizer stream) show a significant increase in noise level. For instance, a variation in the emitted noise of more than $60 \mathrm{~dB}$ has been reported for an oxyfuel burner which depends on fuel-oxygen ratio, mixing rate, and fired duty [6]. Song in [8] examined a nonpremixed, oxyfuel burner firing natural gas with a constant pure oxygen-to-fuel ratio at various heat release rates, as well as with a constant heat release rate and varying pure oxygen to fuel ratio. In both cases, by increasing heat release rate or oxygen flow rate, the combustion noise level was increased up to about $30 \mathrm{~dB}$. However these experimental studies just deal with the combustion noise in high-level oxygen enhancement regime which only can be employed in certain industries. While low-level $\mathrm{O}_{2}$ enhanced combustion (with $21 \%$ up to $30 \%$ oxygen by 
volume in oxidizer stream) has a prominent feature that a substantial improvement in flame properties and combustion efficiency can be achieved with only a few modifications to be made to the existing combustion equipment e.g. burners and, as a consequence, can be employed in various combustion systems [6]. Previous studies have suggested that Lowlevel oxygen enrichment not only costs less among these three enhancement regimes, but has also a positive impact on heating rate increase and fuel saving [3] and efficiency [9] in furnaces, fuel consumption and flue gases reduction in a gas turbine [10], thermal efficiency increase and fuel consumption and unburned hydrocarbons decrease in a diesel engine [11], and a higher combustion efficiency in a combustion chamber with heat exchanger [12]. In such circumstances, noise level will play an important role in the feasibility of using low-level oxygen enhanced systems in burners while it has not been yet addressed in low level OEC or combustion noise studies.

When it comes to the combustion noise, many studies have adopted the dominance of heat release fluctuations as origin of combustion noise source term [13]. Liu et al. have proposed a direct relationship between the sound emission near flame surfaces and the heat release rate employing a Direct Numerical Simulation [14]. In addition to the relation between heat release rate fluctuations and combustion noise, the effect of flame structure on combustion noise emission has also been studied. Xiong and Jiang carried out a numerical investigation about shear layer effect on sound generation in a non-premixed jet flame. They found that distortion of flame surface in the vicinity of the burner nozzle affects the peak and its frequency in the noise spectrum [15]. Shoji et al. experimentally studied relation between flame structure and mean velocity/vorticity fields and its effect on heat release fluctuation and the resulting direct combustion noise radiated from a lean-premixed $\mathrm{H}_{2}$ /air turbulent jet flame. They observed a direct correlation between pressure and heat release rate fluctuations and distinguished two peaks in heat release rate spectrum and sound pressure level respectively generated by global heat release fluctuations (at $\mathrm{f}=500 \mathrm{~Hz}$ ) and vortical flame structures (at $\mathrm{f}=940 \mathrm{~Hz}$ ) [16].

From the literature above it is concluded that the noise generation in air combustion are significantly affected by variation in both heat release rate and flame structure. On the other hand, when oxygen concentration is enhanced in air stream, heat release rate as well as flame characteristics remarkably change [17], combustion process features a higher sensible enthalpy and a higher flame temperature [18], and chemical pathways change [19]. However, the effect of this oxygen enhancement on the heat release rate fluctuations and consequently the associated noise generation have not yet been investigated and there is a clear gap in the literature on analysing noise generation mechanism and emission in an oxygen-enhanced combustion system. Furthermore, all simulations mentioned in the literature for 
studying flame characteristics in OEC have used RANS modelling to investigate steady flame characteristics and thermal calculations, which cannot enable analysing ion temporal variation of flame characteristics such as heat release rate and their contribution in noise generation. In the present work, a Large Eddy Simulation (LES) of an oxygenenhanced combustion system will be conducted for the first time in order to: (i) gain a fundamental understanding into the spatial and temporal characteristics of the OEC turbulent flame, (ii) understand the underlying mechanism of noise generation in OEC systems, (iii) differentiate the various noise sources including heat release rate and mole consumption and production rate contributing to the total emitted noise in an OEC turbulent flame, and (iv) performing a parametric study to examine the influence of the system deterministic variables including $\mathrm{O}_{2}$ concentration on the contribution of different sources to the noise pressure level.

Achievement of this deep insight into an OEC flame dynamics and mechanism of noise generation and emission is beneficial to reform reduced order models, such as methods based on linearized Navier-Stokes equations, and to validate methods which are employing RANS modelling in aeroacoustic simulations. The parametric study is advantageous to industry in the view point of assessing worthwhile data to predict the feasibility of using OEC in combustion systems such as furnaces.

This paper has been organized as follows: section 2 gives an overview of the hybrid method, Lighthill analogy for reactive flows and combustion modeling. In sections 3, and 4, solution settings, and DLR-A flame configuration are described. Then the article is followed by results in section 5, which are presented and discussed in three subsections to represent simulation validation, air-fuel combustion noise results, and the effect of enhanced oxygen on combustion noise. The discussion of OEC noise falls in the scope of this section. Some conclusions are drawn in section 6.

\section{Theoretical formulation}

\subsection{Hybrid method}

In order to describe the combustion noise, multiple processes have to be considered. Large range of scales from acoustic wave length to flame thickness, kinetic chemistry with multi-steps reactions, and the turbulence effects, make combustion noise problem complicated to precisely resolve. This problem needs to reproduce the unsteady turbulent combustion, and to capture acoustic source terms and their propagation. Two main developed approaches in this field are direct numerical simulation (DNS) method and hybrid method. Due to the developments in numerical simulation, DNS method has been used in a few recent numerical studies [20]. While hybrid methods are pioneer in combustion noise simulations taking advantage of the separation between length scales of a subsonic flow field and the acoustic 
field generated by this flow. In this method flow-field characteristics is measured or calculated using a DNS, LES, or URANS simulation and acoustic pressure can be estimated with different approaches e.g. acoustic analogy, acoustic perturbation equations, and stochastic methods. Zhang et al. estimated combustion generated noise through combination of a premixed flame experiment $\mathrm{OH}$ radical data and an analytical solution of Lighthill analogy [21]. Livebardon et al. combined LES and an actuator disk theory to predict combustion noise in a combustion chamber of a helicopter engine [22]. In another work, a LES is combined with advanced System Identification by Merk et al. to simultaneously infer models for the combustion noise sources and the dynamic response to velocity fluctuations of a prernixed turbulent flame. They predicted the spectral distribution of sound pressure within the combustor with acceptable qualitative and quantitative agreement against measurements [23]. Another study predicted far-field combustion noise from helicopter and aircraft propulsion systems with LES of a combustion chamber sector, an analytical propagation model at the combustor exit, and a far-field acoustic propagation through a variable exhaust temperature [24]. The results of these researches reveal that the hybrid method is efficient in predicting combustion noise. The advantage of LES is that a few models are introduced and unsteady coupling between chemistry and turbulence is conserved. Therefore in this study a Large Eddy Simulation with an analytical solution for Lighthill analogy is combined to investigate oxygen-enhanced combustion. Fig. 1 presents the flowchart of the procedure taken in this work to predict the combustion noise.

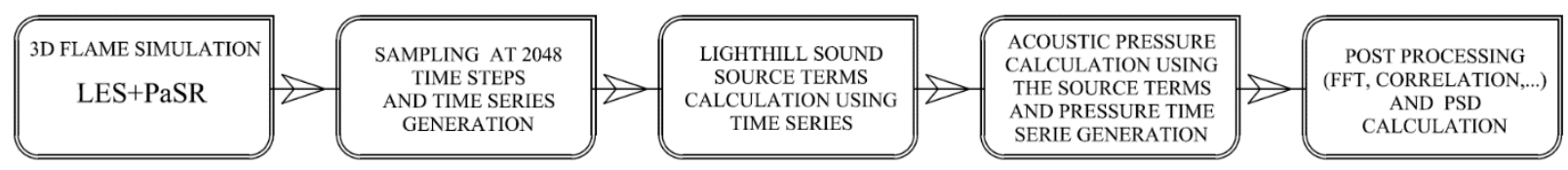

Fig. 1 Flowchart of the combustion noise prediction process used in this study

\subsection{Flow and Combustion modeling}

In Large Eddy Simulation system of equations are redefine to reconstruct the characteristics of turbulent flows. In this section the Favre-averaged conservation equations for mass, momentum, mole fraction, and energy are presented in equations 1 to 4 according to [25]. These equations are discretized and solved utilizing OpenFOAM open source software to simulate turbulent combustion [26].

$$
q_{t}(\bar{r})+\tilde{\mathrm{N}} \cdot\left(\bar{r} u_{i}\right)=0
$$




$$
\begin{aligned}
& \Phi_{t}\left(\bar{r} u_{i}\right)+\tilde{N} \cdot\left(\bar{r} u_{i} u_{j}\right)=-\tilde{\mathrm{N}} \cdot \bar{p}+\tilde{\mathrm{N}} \cdot\left(t_{i j}-\bar{r}\left(\begin{array}{cc}
2 & u_{i} u_{j}-\stackrel{\circ}{u_{i}} u_{j}
\end{array}\right)\right)+\bar{r} g \\
& \text { I }_{t}\left(\bar{r} Y_{k}\right)+\tilde{\mathrm{N}} \cdot\left(\bar{r} u_{i} Y_{k}\right)=\tilde{\mathrm{N}} \cdot\left(\overline{V_{k, i} Y_{k}}-\bar{r}\left(u_{i} Y_{k}-{\stackrel{O}{u} Y_{i}}_{k}\right)\right)+\overline{u_{k}}
\end{aligned}
$$

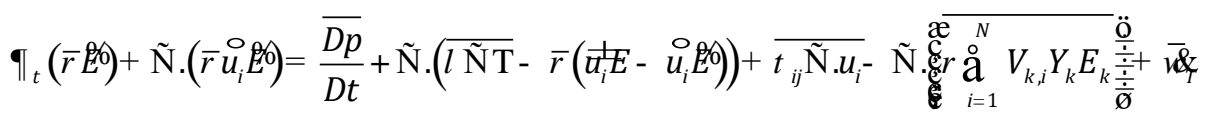

where $\overline{D p} / D t=\partial \bar{p} / \partial t \overline{u_{i}\left(\partial p / \partial x_{i}\right)}$ and $\bar{\rho}, \tilde{Y}_{i}, \stackrel{\circ}{i}_{i}$ and $\tilde{E}$, respectively are the filtered density, species mass fraction, velocity and total energy. Averaging produces terms and closure models need to be used. Hence the residual stress $\stackrel{2}{u_{i}} u_{j}-\stackrel{\circ}{u_{i}} u_{j}$, scalar fluxes $\stackrel{2}{u_{i}} Y_{k}-\stackrel{\circ}{u_{i}} Y_{k}$ and $\stackrel{\leftrightarrow}{u_{i}} E-\stackrel{\circ}{u_{i}} \stackrel{\circ}{E}$, are modeled using a one equation subgrid model [27]. Fick's law relates the diffusive flux of species to the filtered mass fraction gradient and Fourier law is used to estimate thermal diffusion with the gradient in the temperature [28].

$$
\begin{gathered}
\overline{V_{k, i} Y_{k}}=-\bar{\rho} \overline{D_{k}} \frac{\partial \tilde{Y}_{k}}{\partial x_{i}} \\
\overline{\lambda \nabla \mathrm{T}}=\bar{\lambda} \nabla \tilde{T}
\end{gathered}
$$

The diffusion coefficients are modeled as $D_{k}=\mu / S c_{k}$ and $\lambda=\mu / \operatorname{Pr}$, with $S c_{k}$ is the Schmidt number and $\operatorname{Pr}$ is the Prandtl number. The following assumptions are also made: the buoyancy effect is considered as insignificant due to small Richardson number, and Lewis number is presumed to be unity which is a reasonable assumption in turbulent flame simulations [29].

The term, $\overline{u_{i}\left(\partial p / \partial x_{i}\right)}$ is estimated as $\stackrel{\circ}{u_{i}}\left(\boldsymbol{\Phi} / \bar{p} / \uparrow x_{i}\right)$. Total energy, $\tilde{E}$, includes $\tilde{h}-\bar{p} / \tilde{\rho}+\frac{1}{2} \tilde{u}^{2}+k$ in which enthalpy is assessed by $\tilde{h}=\sum_{i}\left(\tilde{Y}_{i} h_{i, f}^{\theta}\right)+\sum_{i}\left(\tilde{Y}_{i} \int_{T_{0}}^{\tilde{T}} C_{p, i}(T) d T\right)$ with $h_{i, f}^{\theta}$ and $C_{p, i}$ as the formation enthalpy and specific heat at constant pressure for each species, respectively and $k=0.5\left(u^{2}-\theta^{2}\right)$ is the subgrid-scale kinetic energy.

To model the turbulence-chemical reaction interaction, the filtered reaction rate $\overline{\dot{\omega}}_{k}$ is modeled with partially stirred reactor combustion model [30]. In this model, each computational cell is considered to be a reactor in which the 
reactions occur in a fraction of its volume. This volumetric fraction $(\kappa)$ is computed using the turbulent flow and combustion characteristics time scales:

$$
\begin{gathered}
\kappa=\frac{\tau_{\text {chem }}}{\tau_{\text {mixing }}+\tau_{\text {chem }}} \\
\tau_{\text {mixing }}=\sqrt{\frac{k}{\varepsilon}\left(\frac{k}{\varepsilon}\right)^{1 / 2}} \\
\frac{1}{\tau_{\text {chem }}}=\max \left\{\frac{-\dot{\omega}_{F}}{\rho Y_{F}}, \frac{-\dot{\omega}_{O_{2}}}{\rho Y_{O_{2}}}\right\}
\end{gathered}
$$

Then mean reaction rate in each cell is calculated using volumetric fraction and rate of change of species concentration:

$$
\overline{\dot{\omega}}_{i}=\kappa \frac{C_{i, 1}-C_{i, 0}}{\Delta t}
$$

Species concentration is computed through the Jones-Linstedt chemical mechanism with six species and four reactions [31].

\subsection{Lighthill analogy for reactive flows}

In most cases, experimental data on noise level is only available in the far-field. However, acoustic propagation calculation by means of a numerical simulation in an enough extended domain is computationally very expensive. To control the simulation cost, acoustic analogy can be employed as a method for acoustic propagation calculation. In this work, the Lighthill analogy is applied to the combustion source terms to calculate direct noise pressure perturbations. Lighthill analogy is derived from conservation equations, and its derivation is explained in detail in [32]. The final form of the Lighthill equation is:

$$
\left(\frac{1}{c_{0}^{2}} \frac{\partial^{2}}{\partial t^{2}}-\nabla^{2}\right) p^{\prime}=\frac{\partial^{2}}{\partial x_{i} \partial x_{j}}\left(\rho u_{i} u_{j}-\tau_{i j}\right)-\frac{\partial^{2} \rho_{e}}{\partial t^{2}}
$$

In this equation, $c_{0}$ is the sound velocity in the environment and is considered to be constant. $u$ is the propagation medium particle velocity and $\tau_{i j}$ is the viscous stress tensor. $\rho_{e}$ is known as excess density which is defined as 
$\rho_{e}=\left(\rho-\rho_{0}\right)-1 / c_{0}^{2}\left(p-p_{0}\right)=\rho^{\prime}-p^{\prime} / c_{0}^{2}$ and vanishes in the farfield. Using thermodynamic relations and energy equation for a gas consist of $N$ reacting species; the inhomogeneous Lighthill equation is rewritten as [33]:

$$
\begin{aligned}
& \frac{1}{c_{0}^{2}} \frac{\partial^{2} p^{\prime}}{\partial t^{2}}-\nabla^{2} p^{\prime}=S_{1}+S_{2}+S_{3}+S_{4} \\
& S_{1}=-\frac{\partial}{\partial t}\left[\frac{\alpha \rho_{0}}{c_{p} \rho}\left(\begin{array}{c}
\left.\left.\left.\sum_{m=1}^{N} \frac{\partial h}{\partial Y_{m}}\right|_{T, p, Y_{n}} \omega_{n}-\left(\left.\frac{\partial h}{\partial \rho}\right|_{p, Y_{m}}\right) \times\left(\left.\sum_{m=1}^{N} \frac{\partial \rho}{\partial Y_{m}}\right|_{T, p, Y_{n}} \omega_{n}\right)\right)\right] \\
-\left.\sum_{m=1}^{N} \frac{\partial h}{\partial Y_{m}}\right|_{T, p, Y n} \nabla \cdot J_{n}+\frac{\partial q_{i}}{\partial x_{i}}-\tau_{i j} \frac{\partial u_{i}}{\partial x_{j}}
\end{array}\right)\right] \\
& S_{2}=\frac{\partial^{2}}{\partial x_{i} \partial x_{i}}\left(\rho u_{i} u_{j}-\tau_{i j}\right) \\
& S_{3}=\frac{1}{c_{0}^{2}}\left(\left(1-\frac{\rho_{0} c_{0}^{2}}{\rho c^{2}}\right) \frac{D p}{D t}-\frac{\left(p-p_{0}\right)}{\rho} \frac{D \rho}{D t}\right)
\end{aligned}
$$

$S_{1}$ is the monopole source of sound which generates direct combustion noise caused by volumetric fluctuation due to unsteady heat release rate, non-isomolar combustion, species diffusion, heat conduction, and viscous dissipation. $S_{2}$ is the sound source of quadrupole type associated with the velocity fluctuations. It scales with the eighth power of Mach number and in open flames with small Mach number is insignificant. $S_{3}$ also scales with $\mathrm{M}^{8}$ and its value is negligible since throughout a low Mach number open flame, the pressure does not vary a lot and $\rho_{0} c_{0}^{2}=\gamma p$ [34]. $\mathrm{S}_{4}$ is dipole and scales with the sixth power of Mach number and describes the acceleration of density inhomogeneities in the flowfield. It has been shown that monopole sound source is stronger than dipole and quadrupole sources by the coefficient of $\mathrm{M}^{2}$ and $\mathrm{M}^{4}$, respectively [32]. This relation is simplified with the following assumptions:

- Considering the Mach number of the DLR-A flame (M=0.123), dipole $\left(S_{4}\right)$ and quadrupole $\left(S_{2}, S_{3}\right)$ sound sources are not significant compared to monopole sound source [35] and will not be discussed in this work.

- Because of the turbulent nature of the flame, laminar heat and species diffusion phenomena and viscosity in $\mathrm{S}_{1}$ are considered as insignificant.

Finally, mole consumption and production rate and unsteady heat release rate fluctuations are maintained to be analyzed in this simulation. 
Another assumption in solving the Lighthill equation is flame compactness. If an open turbulent flame be considered as illustrated in Fig. 2, flame brush acoustic thickness is taken as the cube root of the volume enclosed by the flame brush [36]. When the radiated sound wavelength is larger than flame brush acoustic thickness in the farfield, the flame is assumed acoustically compact. i.e., for an observer in the farfield, two sound sources are similar to a centralized source. Free space Green function can be applied to Eq. (10) using flame compactness assumption, to develop its solution for an unbounded environment [37]. The resulting farfield sound pressure fluctuation then is given by:

$$
4 \pi|x|\left(p-p_{0}\right)(x, t)=-\frac{\partial}{\partial t} \int\left[\frac{\alpha \rho_{0}}{c_{p} \rho}\left(\left.\sum_{m=1}^{N} \frac{\partial h}{\partial Y_{m}}\right|_{T, p, Y_{n}} \omega_{m}-\left.\frac{\partial h}{\partial \rho}\right|_{p, Y_{m}}\left(\left.\sum_{m=1}^{N} \frac{\partial \rho}{\partial Y_{m}}\right|_{T, p, Y_{n}} \omega_{m}\right)\right)\right] d^{3} y
$$

In deriving this equation, an approximation has been made that there is a large distance between observer and sound sources in comparison with flame brush acoustic thickness.

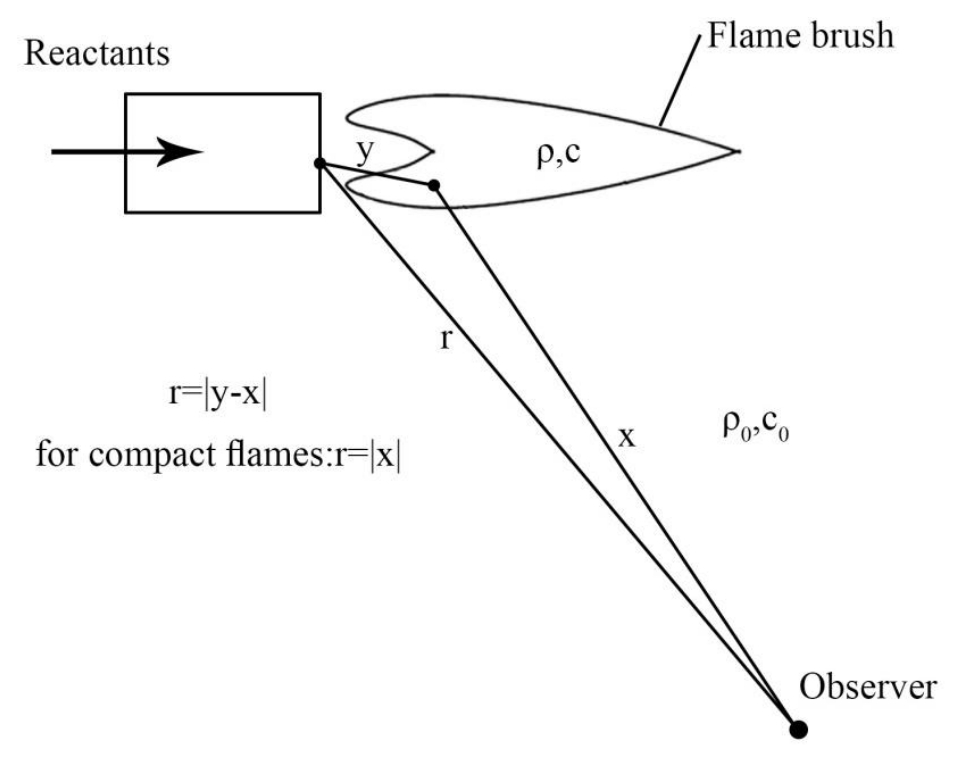

Fig. 2 Flame schematic showing the coordinates for acoustic analysis [38].

To solve this equation, the right-hand side should be rewritten with some assumptions. The gas mixture is taken as an ideal gas, $\alpha=1 / T$, and $\alpha / c_{p}=(\gamma-1) / c_{0}^{2}$. Sound speed, $c_{0}$, and $\gamma$ are assumed to be constant and temperature independent. $\left(\partial h / \partial Y_{m}\right)_{T, p, Y_{n}}$ is the enthalpy of $\mathrm{m}^{\text {th }}$ species, $h_{m}$, Considering the following relations: 


$$
\begin{gathered}
\left.\sum_{m=1}^{N} \frac{\partial \rho}{\partial Y_{m}}\right|_{T, p, Y_{n}} \omega_{n}=-\rho \sum_{m=1}^{N} \frac{\overline{M W}}{M W_{m}} \omega_{m} \\
\left.\frac{\partial h}{\partial \rho}\right|_{p, Y_{n}}=\left.\frac{\partial h}{\partial T} \frac{\partial T}{\partial \rho}\right|_{p, Y_{n}}=-c_{p} \frac{T}{\rho}
\end{gathered}
$$

Source terms of Eq. (3) can be reformulated as follows:

$$
\begin{gathered}
-\frac{\partial}{\partial t} \int\left[\frac{\alpha \rho_{0}}{c_{p} \rho}\left(\left.\sum_{m=1}^{N} \frac{\partial h}{\partial Y_{m}}\right|_{T, p, Y_{n}} \omega_{m}\right)\right] d^{3} y=-\frac{\gamma-1}{c_{0}^{2}} \frac{d}{d t} \int(\dot{q}) d^{3} y \\
-\frac{\partial}{\partial t} \int\left[\frac{\alpha \rho_{0}}{c_{p} \rho}\left(-\left.\frac{\partial h}{\partial \rho}\right|_{p, Y_{m}}\left(\left.\sum_{m=1}^{N} \frac{\partial \rho}{\partial Y_{m}}\right|_{T, p, Y_{n}} \omega_{m}\right)\right)\right] d^{3} y=-\frac{d}{d t} \int\left(\frac{\rho_{0}}{\rho}(\overline{M W}) \times\left(\sum_{n=1}^{N} \frac{\omega_{n}}{M W_{n}}\right)\right) d^{3} y
\end{gathered}
$$

where $\dot{q}, \overline{M W}, M W_{n}$ and $\omega_{n}$, respectively are the heat release rate per unit volume, mixture molar weight, individual species molar weight and the reaction rate. These parameters are determined by combustion Large Eddy Simulation. In order to calculate emitted acoustic pressure using Lighthill's method, the volumetric integral is replaced with the sum of source terms over the whole simulation domain.

$$
4 \pi|x|\left(p-p_{0}\right)_{\text {analytical }}(x, t)=-\frac{d}{d t} \frac{\gamma-1}{c_{0}^{2}} \sum_{V}(\dot{q})-\frac{d}{d t} \sum_{V}\left(\frac{\rho_{0}}{\rho}(\overline{M W}) \sum_{n=1}^{N} \frac{\omega_{n}}{M W_{n}}\right)
$$

By assuming $n=\frac{\rho}{\overline{M W}}$ as the number of moles per unit volume and $\dot{n}=\sum_{n=1}^{N} \frac{\omega_{n}}{M W_{n}}$ as the molar consumption and production rate per unit volume, Eq. (5) is rewritten as:

$$
4 \pi|x|\left(p-p_{0}\right)_{\text {analytical }}(x, t)=-\frac{\gamma-1}{c_{0}^{2}} \frac{d}{d t} \sum_{V}(\dot{q})-\frac{d}{d t} \sum \frac{\rho_{0} \dot{n}}{n}
$$

Only sound waves with wavelength larger than flame brush acoustic thickness can be predicted using this equation. This does not affect combustion noise investigation because high-frequency sound waves do not have a key role combustion noise pressure level [37] and can be neglected in this calculation. 


\section{Solution settings}

The computational domain is a three-dimensional cylinder with dimensions of $35 D_{\text {ref }} \times 2 \pi \times 120 D_{\text {ref }}$ in radial, circumferential, and axial directions. The circumferential direction is equally spaced while a structured non-uniform grid is used to discretize the computational domain in the other two directions. Cells are refined near the jet nozzle and in the shear layer region. The radius of the fuel jet and coflow are resolved by 20 and 88 cells. The grid in circumferential and axial directions uses 48 and 640 cells, respectively. Therefore a total number of 3.32 million cells are achieved by this resolution. Maximum and minimum filter widths are $2.32 \times 10^{-4}$ near the nozzle shear layer and $7 \times 10^{-3}$ at the outflow plane corresponding to $\Delta=\sqrt[3]{V_{\text {cell }}}$ relation, where $\Delta$ is filter width and $V_{\text {cell }}$ is the computational cell volume. Experimental data for velocity in [39] are used to produce inlet velocity profile. A synthetic method with random fluctuations is applied to the velocity profile to produce turbulence in the inlet flow [27]. No-slip boundary condition is applied at the radial boundaries. The convective outflow boundary condition is used at the outflow plane. The temperature of all boundaries is set equal to that of the ambient.

An Euler first-order method is used for time derivation, and a second-order TVD scheme is used for convection term [40]. The pressure implicit with splitting of operators (PISO) algorithm is used for pressure-velocity coupling. The simulation was run over 15 flow-through-time ( 0.34 seconds) to attain a stationary steady solution. The time average

of flow field parameters, $\langle\tilde{A}\rangle$ and their variances, $\left\langle\tilde{A}^{\prime \prime}\right\rangle$ are then collected over 10 flow-through-time of simulation with an averaging in the azimuthal direction according to equations (14-a) and (14-b):

$$
\begin{gathered}
\langle\tilde{A}\rangle(r, y)=\frac{1}{2 \pi T} \int_{\tau}^{\tau+T} \int_{0}^{2 \pi} \tilde{A}(r, \varphi, y, \tau) d \varphi d \tau \\
\left\langle\tilde{A}^{\prime \prime}\right\rangle(r, y)=\frac{1}{2 \pi T} \int_{\tau}^{\tau+T} \int_{0}^{2 \pi}[\tilde{A}(r, \varphi, y, \tau)-\langle\tilde{A}\rangle(r, y)]^{2} d \varphi d \tau
\end{gathered}
$$

To describe the oxygen enhancement effect on the combustion noise generation, air enrichment is applied by increasing oxygen mole fraction in the air stream from 0.21 up to 0.23 , corresponding to $10 \%$ of oxygen enhancement by volume. 


\section{System configuration}

The DLR-A flame considered in this work has been experimentally studied by Meier et al. [39]. The burner consists of a tube of internal diameter of $D_{\text {ref }}=8 \mathrm{~mm}$ and coflow nozzle with a diameter of $140 \mathrm{~mm}$. The fuel has a composition of $22.1 \% \mathrm{CH}_{4}, 33.2 \% \mathrm{H}_{2}$, and $44.7 \% \mathrm{~N}_{2}$ and the stoichiometric mixture fracture is 0.167 . Hydrogen is added to stabilize the flame. The fuel and coflow mean exit velocity is $U_{r e f}=42.2 \pm 0.5 \mathrm{~m} / \mathrm{s}(R e=15,200)$ and $0.3 \mathrm{~m} / \mathrm{s}$, respectively. Parameters used in the calculation are given in Table 1. Spectral noise emission from DLR-A flame is also measured by Singh et al. [41] and the resulted sound pressure level data are available to validate the simulation results.

Table 1 Reference parameters for the reactive jet simulation [42]

\begin{tabular}{ccc}
\hline \hline Parameter & Value & Units \\
\hline$D_{\text {ref }}$ (fuel) & $8 \times 10^{-3}$ & $\mathrm{~m}$ \\
$U_{\text {ref }}$ (fuel) & 42.2 & $\mathrm{~m} / \mathrm{s}$ \\
$a_{\text {ref }}$ & 344.33 & $\mathrm{~m} / \mathrm{s}$ \\
$\rho_{\text {ref }}$ (air) & 1.169 & $\mathrm{~kg} / \mathrm{m}^{3}$ \\
\hline \hline
\end{tabular}

\section{Results and discussion}

\subsection{Flow field}

In this section, the present simulations results of the flow field characteristics in the DLR-A flame for the air-fuel combustion are compared to simulation results [42] and experimental data [39]. Fig. 3 shows that the time-averaged and resolved RMS values of normalized axial velocity and temperature predicted by the current simulations, are in good agreement with the experiment data. Although, some discrepancies are observed in the temperature fluctuation, the overall trend is well predicted using the current LES model.
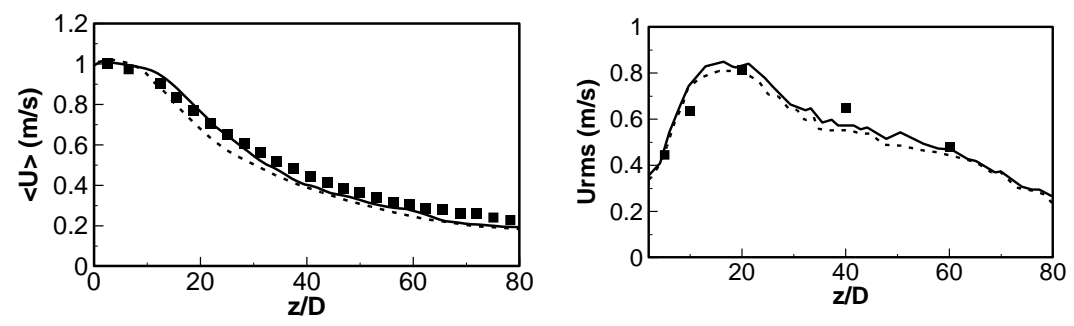

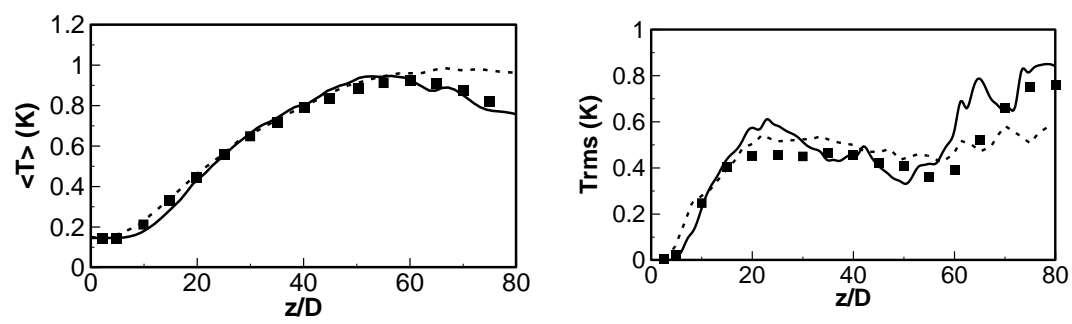

Fig. 3 Mean and RMS values for axial velocity and temperature calculated using the present LES model (solid line) against the experimental data of Meier et al. [39] (symbols) and simulation results of Ihme et al. [42] (dashed line) for (a) $z / D_{r e f}=5$ and (b) $z / D_{r e f}=10$ and (c) $z / D_{\text {ref }}=40$.

In Fig. 4, radial profiles of the simulated time-averaged and RMS values of the normalized streamwise velocity component reveal a good agreement with the measured data in three axial location of $\mathrm{z} / \mathrm{D}=5,10$ and 40 . Velocity profiles are rather underpredicted at the shear layer of the jet stream. This phenomenon may be attributed to the inlet random turbulence generator. Since fluid behavior within the domain is influenced by the synthetic inlet boundary condition, an overestimation of the jet flame decay rate is observed. This has also resulted in differences in the RMS value near nozzle section at $\mathrm{z} / \mathrm{D}=5$.
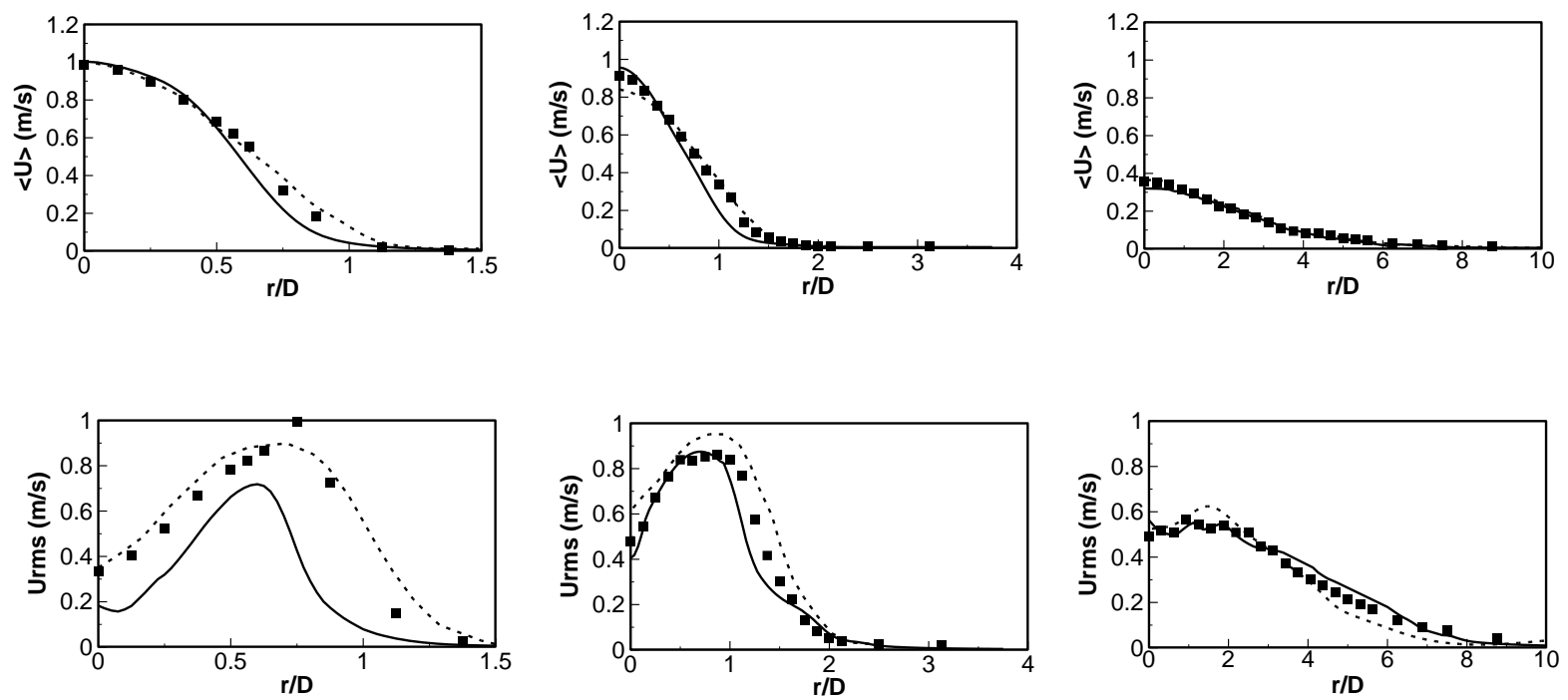

(a)

(b)

(c) 


\section{Fig. 4 Mean and RMS values for velocity calculated using the present LES model against the experimental} data of Meier et al. [39] (symbols) and simulation results of Ihme et al. [42] (dashed line)

$$
\text { for (a) } z / D_{r e f}=5 \text { and (b) } z / D_{\text {ref }}=10 \text { and (c) } z / D_{\text {ref }}=40 \text {. }
$$

Profiles of mean and resolved RMS of normalized temperature in three axial locations are shown in Fig. 5. With the exception of the overprediction of the mean temperature in the near-nozzle section, at $\mathrm{z} / \mathrm{D}=5$, the simulation results for temperature are in good agreement with the measurement. At $\mathrm{z} / \mathrm{D}=5$, the mean temperature is about $10 \%$ overpredicted in the fuel-lean side. This discrepancy can be an effect of the viscosity and mixing-layer thickness overprediction in the near nozzle shear layer which leads to a higher estimation in heat diffusion.

Fig. 6 shows the radial distributions of the time-averaged mass fractions of the major chemical species. A maximum variation of $20 \%$ is observed in prediction of $\mathrm{H}_{2} \mathrm{O}$ mass fraction near the nozzle. This under-prediction can be attributed to the assumption of unity Lewis number for all species, including $\mathrm{H}_{2}$ fuel that results in lower diffusion and consumption for hydrogen on the fuel-rich side of the flame. With increasing distance to the nozzle, at $\mathrm{z} / \mathrm{D}=10$ and $40, \mathrm{CO}_{2}$ and $\mathrm{H}_{2} \mathrm{O}$ radial profiles are more accurately predicted with an acceptable agreement between experiment and simulation.
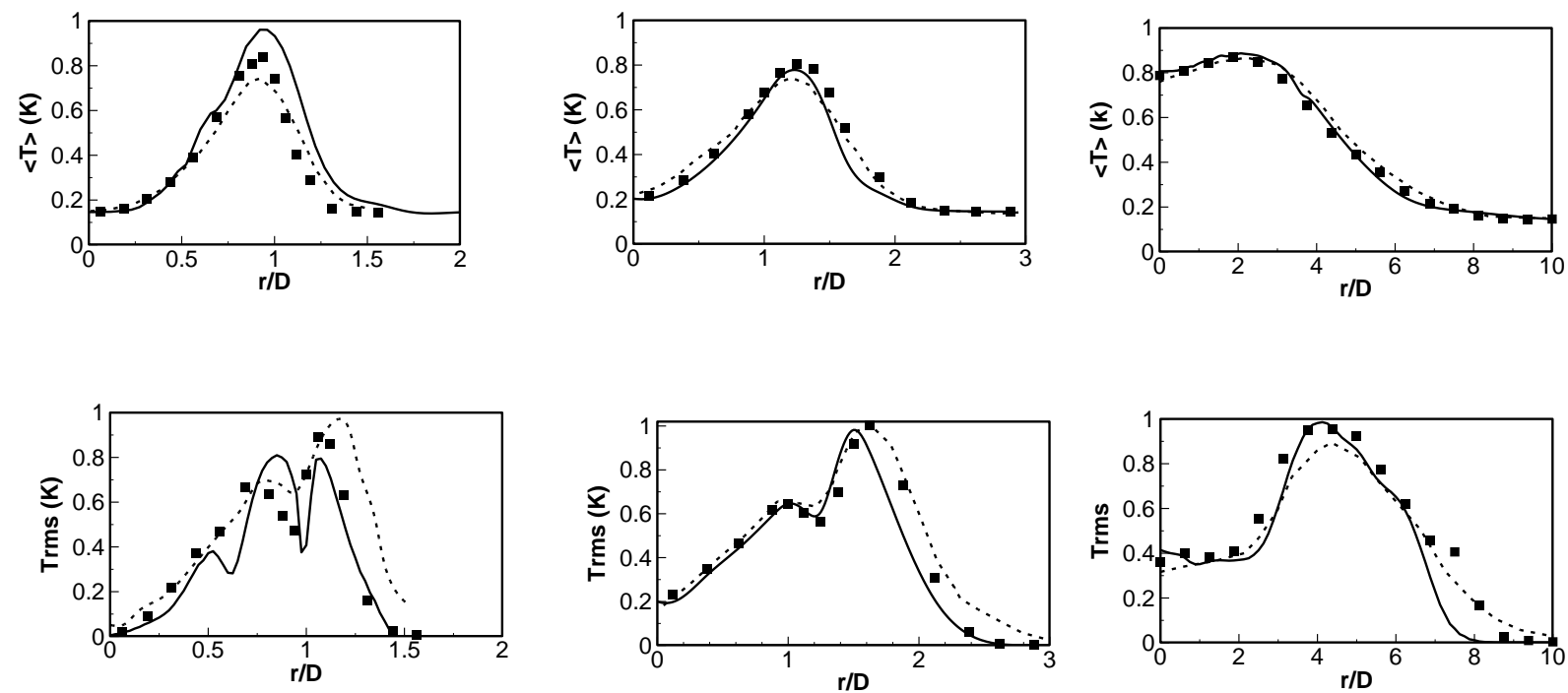

(a)

(b)

(c) 
Fig. 5 Mean and RMS values for temperature calculated using the present LES model against the experimental data of Meier et al. [39] (symbols) and simulation results of Ihme et al. [42] (dashed line) for (a) $z / D_{r e f}=5$ and (b) $z / D_{r e f}=10$ and (c) $z / D_{r e f}=40$.

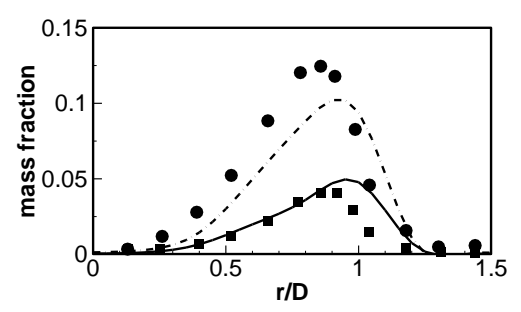

(a)

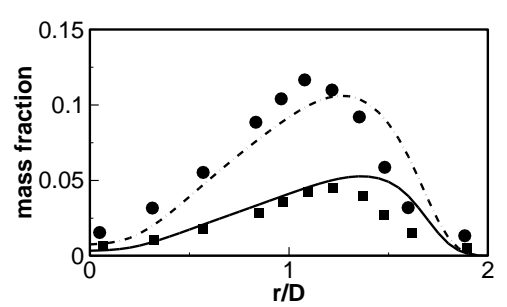

(b)

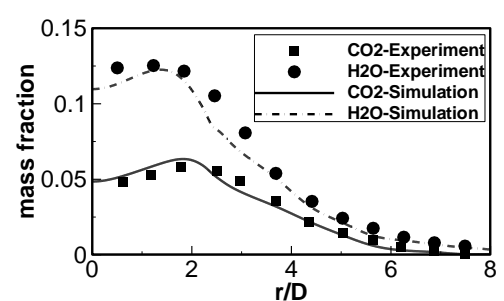

(c)

Fig. 6 Mean and RMS values for mass fraction of $\mathrm{CO}_{2}$ and $\mathrm{H}_{2} \mathrm{O}$ calculated using the present LES model against the experimental data of Meier et al. [39] for (a) $z / D_{r e f}=5$ and (b) $z / D_{r e f}=10$ and (c) $z / D_{r e f}=40$.

\section{Noise from the DLR-A flame}

As demonstrated in equation 13, unsteady combustion induces a monopole (volume) source term in the acoustic wave equation [41]. In a low Mach number flow, the monopole source of combustion noise is far larger than the sound due to the other dipole and quadrupole source mechanisms ([32]). Therefore farfield acoustic pressure for DLR-A flame with Mach number of 0.123 is calculated from two monopole source terms in equation 13: fluctuating heat release rate and fluctuating mole consumption and production rate.

To simplify reference to the source terms in the rest of the article, they are represented by $H R R=-\left(\gamma-1 / c_{0}^{2}\right)(d \dot{q} / d t)$ and $M C P R=-\left(\rho_{0} d(\dot{n} / n) / d t\right)$. These source terms are calculated by post-processing the LES data. Considering Nyquest sampling theorem, simulated flow properties are recorded with a 20 time steps period which equals to $10^{-5}$ seconds throughout 40960 time steps. Total sampling time is 0.021 seconds which corresponds to approximately seven acoustic-flow-through-time. Following experimental setup, the observer is located in the $90^{\circ}$ sideline direction, at $\mathrm{x}=0$, $\mathrm{y}=50 D_{\text {ref }}$ and $\mathrm{z}=0$. The grid cut-off frequency corresponds to the Strouhal number of 0.7 .

Two source terms are sampled at four probes which are located on the mean stoichiometric mixture fraction surface at $z / D_{\text {ref }}=10,20,30$ and 40relative to the nozzle tip in each flame. Since frequency content and amplitude of a sound wave is in accordance with its source, a fast Fourier transform is applied to the sampled HRR and MCPR signals 
to discover their amplitude and frequency range. The corresponding frequency spectra for two source terms as a function of the Strouhal number, $s t=f D_{\text {ref }} / U_{\text {ref }}$, are shown in Fig. 7. The shapes of the spectra at all probes are similar such that magnitude of both source terms is predominant in the low Strouhal numbers. It can be concluded that high-frequency sound waves do not play a key role in combustion noise evaluation. This result is in agreement with previous findings of Mühlbauer et al.[43], Ihme and Pitsch [42], and Bui et al. [44] that have carried out combustion noise numerical simulation and implied that combustion noise is predominant in low frequencies. It also is obvious that the magnitude of the MCPR term is significantly smaller than the HRR.
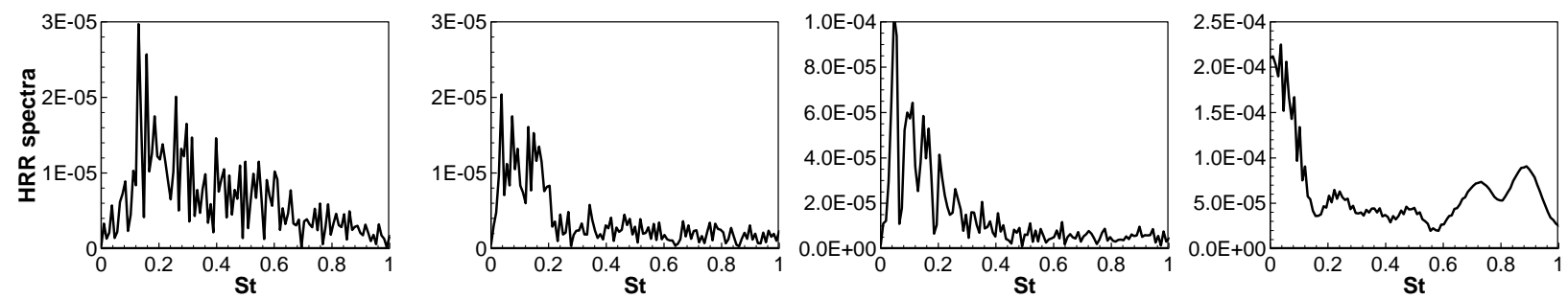

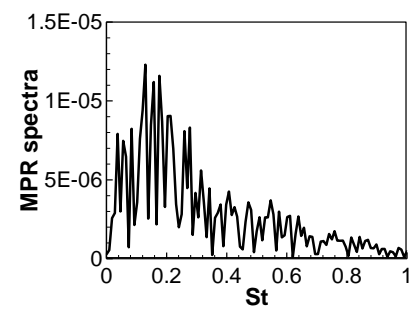

(probe-1)

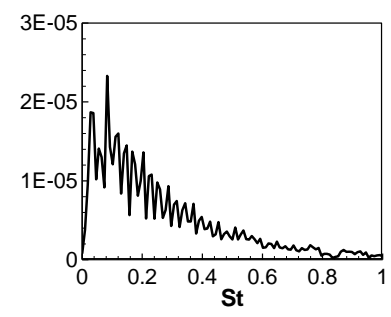

(probe-2)

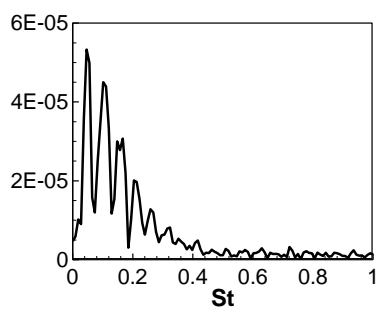

(probe-3)

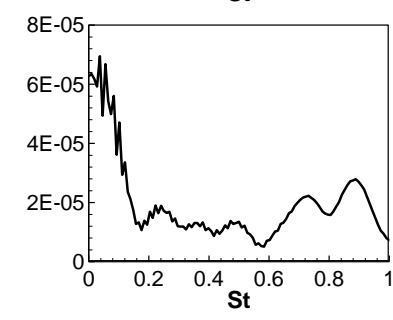

(probe-4)

Fig. 7 Spectrum of HRR and MCPR at four sampling probes located on the stoichiometric mixture fraction surface, for DLR-A flame.

An evaluation of the contribution from different source terms to the total sound pressure level as a function of Strouhal number is shown in Fig. 8. A comparison of the present results with the experimental data of Singh et al. [41] and numerical results by Ihme et al. in [42] are illustrated in Fig. 8. Solid lines represent simulation results and experimental data are shown by symbols. 


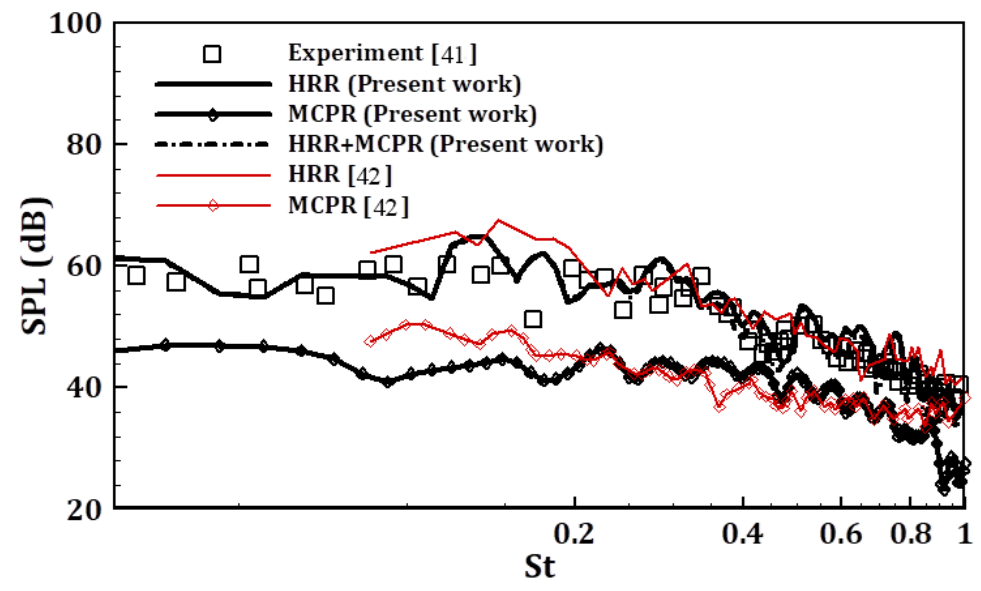

Fig. 8 Total sound pressure level and each source term contribution at $\mathrm{x}=\mathbf{0}, \mathrm{y}=50, D_{\text {ref }}$ and $\mathrm{z}=\mathbf{0}$ calculated using the present LES model against the experimental data (symbols) of [41] and simulation (red and gray lines) of [42], for DLR-A flame.

There is a relatively uniform amplitude for total sound pressure level up to $\mathrm{St}=0.3$, then a roll-off which reveals the low-frequency nature of the combustion noise. Source terms contributions in sound pressure level are calculated separately using the numerical simulation. The sound arising from the MCPR source term is more than ten decibels smaller than fluctuating heat release rate and so is not an efficient contributor to the overall sound pressure level in low and mid frequencies. At higher frequencies, this contribution increases slightly, but the dominant source term remains fluctuating heat release rate at all frequencies. This indicates that the heat release rate source term characterizes the emitted sound wave and mole consumption and production source term can be considered as negligible in combustion noise calculations.

\section{Effect of air enrichment on DLR-A flame combustion noise characteristics}

To gain an insight into low-level OEC effect on combustion noise, oxygen mole fraction was increased by $10 \%$ in the oxidizer stream. Utilizing OEC in a non-premixed flame changes stoichiometric mixture fraction given by [45]:

$$
Z_{s t}=\left(1+\left(u_{O 2} W_{O 2} / u_{F} W_{F}\right) Y_{F, f u} / Y_{O 2, o x}\right)^{-1}
$$

where $u_{i}, Y_{i}$ and $W_{i}$ represent the stoichiometric coefficient, mass fraction, and molecular weight of species $i$, respectively. The oxidizer stream boundary is shown by the subscript $o x$, and the fuel stream boundary is indicated by 
the subscript $f u$. It is evident from this relation that enhanced oxygen concentration in the air stream represents a higher stoichiometric mixture fraction. In this work, oxygen mole fraction and stoichiometric mixture fraction respectively were changed from the primary value of 0.21 and 0.167 in the DLR-A flame up to 0.231 and 0.1802 in the case fuel is burning in $\mathrm{O}_{2}$ enriched air.

Since only the effect of oxygen enhancement on combustion noise source terms and emitted sound waves are considered, all other boundary conditions including exit velocities of the fuel and oxidizer stream and fuel composition have remained unchanged.

Fig. 9 represents a comparison of the resulted OEC noise with the noise of the DLR-A flame simulation. The results show that compared to DLR-A flame, in the OEC case, the SPL due to the heat release rate fluctuations has been increased and the SPL due to the mole consumption and production rate fluctuation has been decreased.

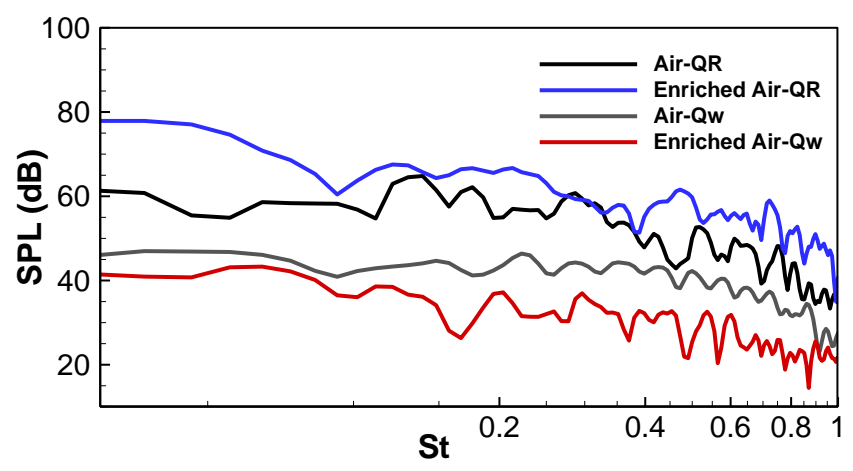

Fig. 9 Comparison of each source term contribution in emitted combustion noise at $\mathrm{x}=\mathbf{0}, \mathbf{y}=50 D_{\text {ref }}$ and $\mathrm{z}=0$, for DLR-A flame and oxygen-enhanced combustion.

An evaluation of the spectrum of both source terms is carried out by using the fast Fourier transform. The results are shown and compared to the DLR-A flame at four points for HRR and MCPR in Fig. 10. A shift towards the higher Strouhal numbers can be observed through the comparison between the results for DLR-A flame and enriched air combustion. Although at probe-3 HRR and MCPR have high amplitudes in the medium and high Strouhal numbers, the dominant SPL still lies in the low Strouhal number range at all probes. The amplitude of HRR spectra is about one order of magnitude higher than that of the MCPR. This implies that MCPR is a rather inefficient noise contributor in low-level oxygen enhanced combustion. 

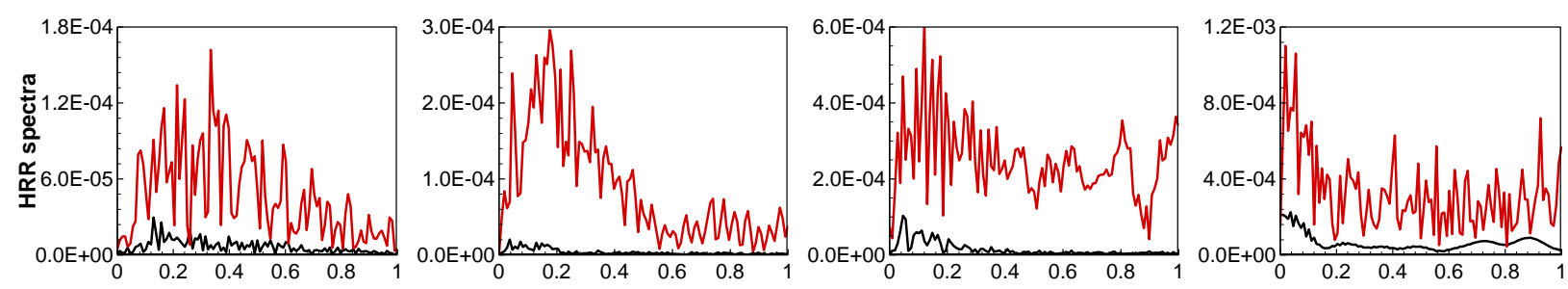

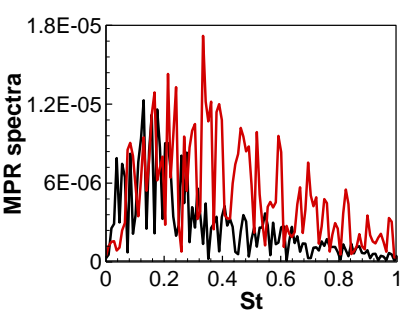

(probe-1)

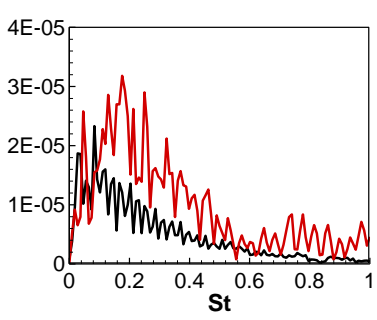

(probe-2)

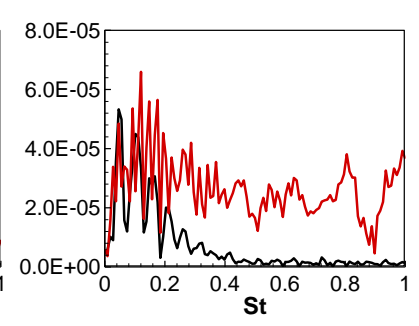

(probe-3)

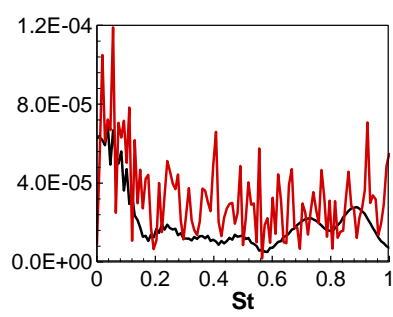

(probe-4)

Fig. 10 Spectrum of HRR and MCPR at four sampling probes located on the stoichiometric mixture fraction surface, for DLR-A flame (black), and oxygen-enhanced combustion (red)

The increment in the spectra of HRR and MCPR can be a consequence of the increase of the magnitude of heat release rate $\dot{q}$, and mole consumption and production rate $\dot{n} / n$, or an increase in the fluctuation rate of these terms. To determine the governing phenomenon, magnitude and fluctuation rate of $(\gamma-1) \dot{q} /\left(c_{0}^{2}\right)$ and $\rho_{0} \dot{n} / n$ terms are investigated. At first, the radial distribution of the $(\gamma-1) \dot{q} /\left(c_{0}^{2}\right)$ and $\rho_{0} \dot{n} / n$ at four sections from the flame nozzle, $z / D_{r e f}=10,20,30$, and 40 are compared for DLR-A flame and $\mathrm{O}_{2}$ enhanced combustion in Fig. 11. It can be seen that the maximum values of both terms have increased for the $\mathrm{O}_{2}$ enhanced combustion case at four sections. For $(\gamma-1) \dot{q} /\left(c_{0}^{2}\right)$, this can be explained by the higher temperature in OEC compared to the combustion with regular air [46], and as a consequence, higher reaction rates which leads to a higher amount of heat release. For $\rho_{0} \dot{n} / n$, it is speculated that the higher temperature leads to a decrease in density which causes an increase in this term. 

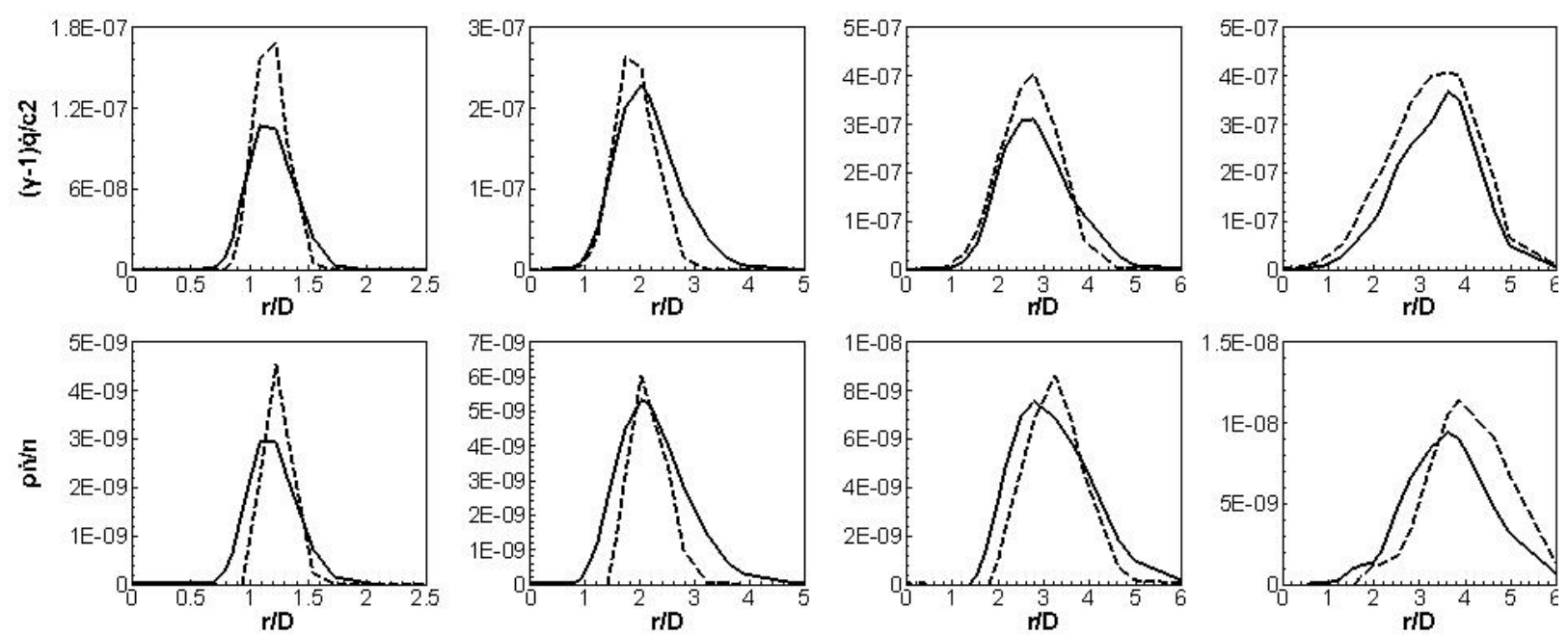

$\mathbf{z} / \mathbf{D}=\mathbf{1 0}$

$\mathbf{z} / \mathbf{D}=\mathbf{2 0}$

$\mathrm{z} / \mathrm{D}=\mathbf{3 0}$

$\mathrm{z} / \mathrm{D}=\mathbf{4 0}$

Fig. 11 The radial distribution of the $(\gamma-1) \dot{q} /\left(c_{0}^{2}\right)$ and $\rho_{0} \dot{n} / n$ at $z / D_{r e f}=10,20,30$, and 40, for DLR-A

flame (solid line), and oxygen-enhanced combustion (dashed line)

Periodicity is calculated using the auto-correlation function, which allows evaluating the fluctuating behavior of $(\gamma-1) \dot{q} /\left(c_{0}^{2}\right)$ and $\rho_{0} \dot{n} / n$. A lower periodicity demonstrates a more periodic signal and consequently a higher value of time derivative of $(\gamma-1) \dot{q} /\left(c_{0}^{2}\right)$ and $\rho_{0} \dot{n} / n$. To compute the periodicity of fluctuating sound source terms, $(\gamma-1) \dot{q} /\left(c_{0}^{2}\right)$ and $\rho_{0} \dot{n} / n$ were sampled at four points. Afterwards, autocorrelation of each source term signal was calculated. Then average time difference between the peak locations was computed. This time difference was utilized as the deterministic parameter of the periodicity. This parameter is calculated at four sampling points and presented in Fig. 12. Compared to the air-fuel combustion, increasing the $\mathrm{O}_{2}$ concentration in the oxidizer stream, causes the source term signals fluctuate more rapid. Decreased periodicity explains the reason why there is a shift toward higher frequencies in the source term spectrum in Fig. 10. It also can be concluded that in this case, the distortion of the flame and the rate of change of source terms increase. 

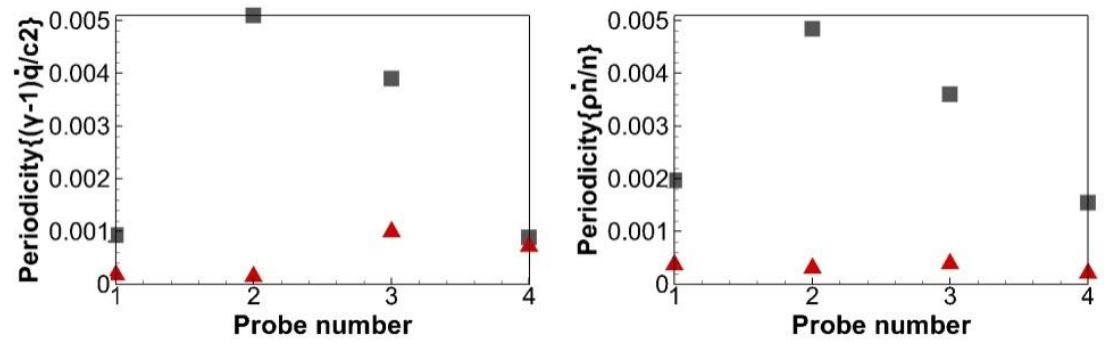

Fig. 12 periodicity of two source terms at four sampling probes located on the stoichiometric mixture fraction surface.

It is expected that increasing in magnitude and fluctuation of $(\gamma-1) \dot{q} /\left(c_{0}^{2}\right)$ and $\rho_{0} \dot{n} / n$ terms lead to an increase in the sound pressure level which is seen for the noise emitted by HRR while this is not the case for MCPR.

The instantaneous temperature distribution and the location of the mean stoichiometric mixture fraction for air-fuel and enriched air-fuel simulations are illustrated in Fig. 13. One observation which can be made from these figures is that although reactants with higher levels of temperature are leaving the flame, a more compact flame is seen for the enriched case. This result can be prescribed by the stoichiometric requirements of the flame formation location, which is shown in Fig. 14 at $z / D_{\text {ref }}=10$ and 40.
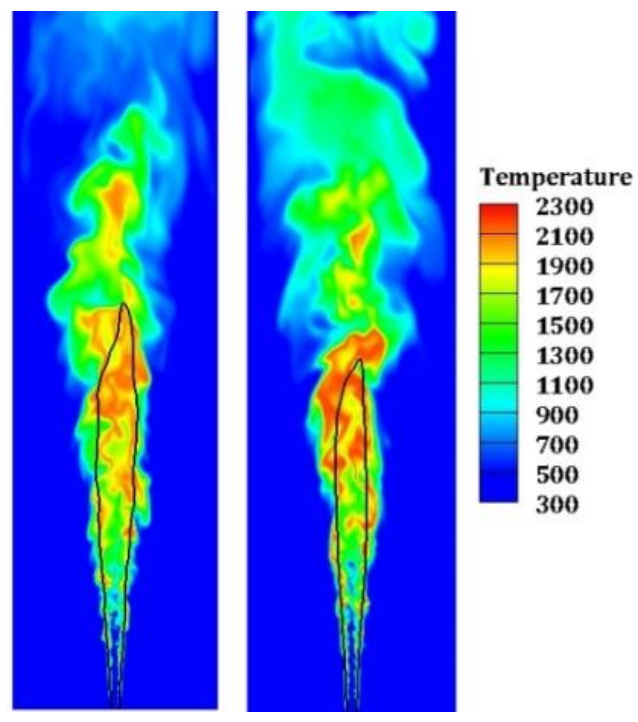

Fig. 13 Instantaneous temperature distribution and the location of the mean stoichiometric mixture fraction for air-fuel (left) and enriched air-fuel (right) simulations 


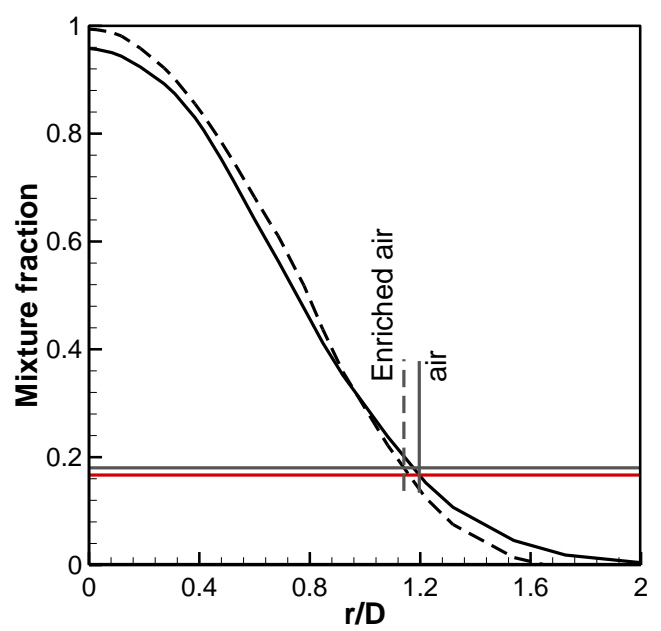

z/Dref $=10$

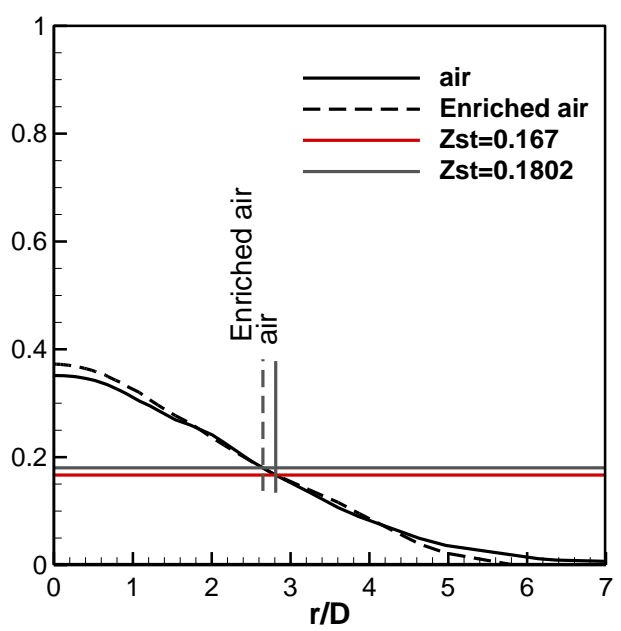

z/Dref $=\mathbf{4 0}$

Fig. 14 Determination of flame location at intersection of mixture fraction profiles and stoichiometric mixture fractions at two sections $z / D_{r e f}=10$ and 40, for DLR-A flame (solid line), and oxygen-enhanced combustion (dashed line)

It can be seen here that by increasing the stoichiometric mixture fraction, the flame sits closer to the oxidizer stream. Another observation in Fig. 13 is a higher temperature for the enriched case at the flame zone. According to equation 8 the reaction rate is dramatically affected by the rate of change of species concentration which is determined by the chemical kinetics. As a result, this temperature enhancement intensifies the mole consumption and production rate. This is described by representing mean species production and consumption rate at two sections, $\mathrm{z} / \mathrm{D}=10$ and 40 , in Fig. 15. The maximum values of mean species production and consumption rate have an overall increment at both sections. These values have also shifted towards the fuel. The latter is more visible in the section farther from the fuel nuzzle at which reaction zone is thicker. 

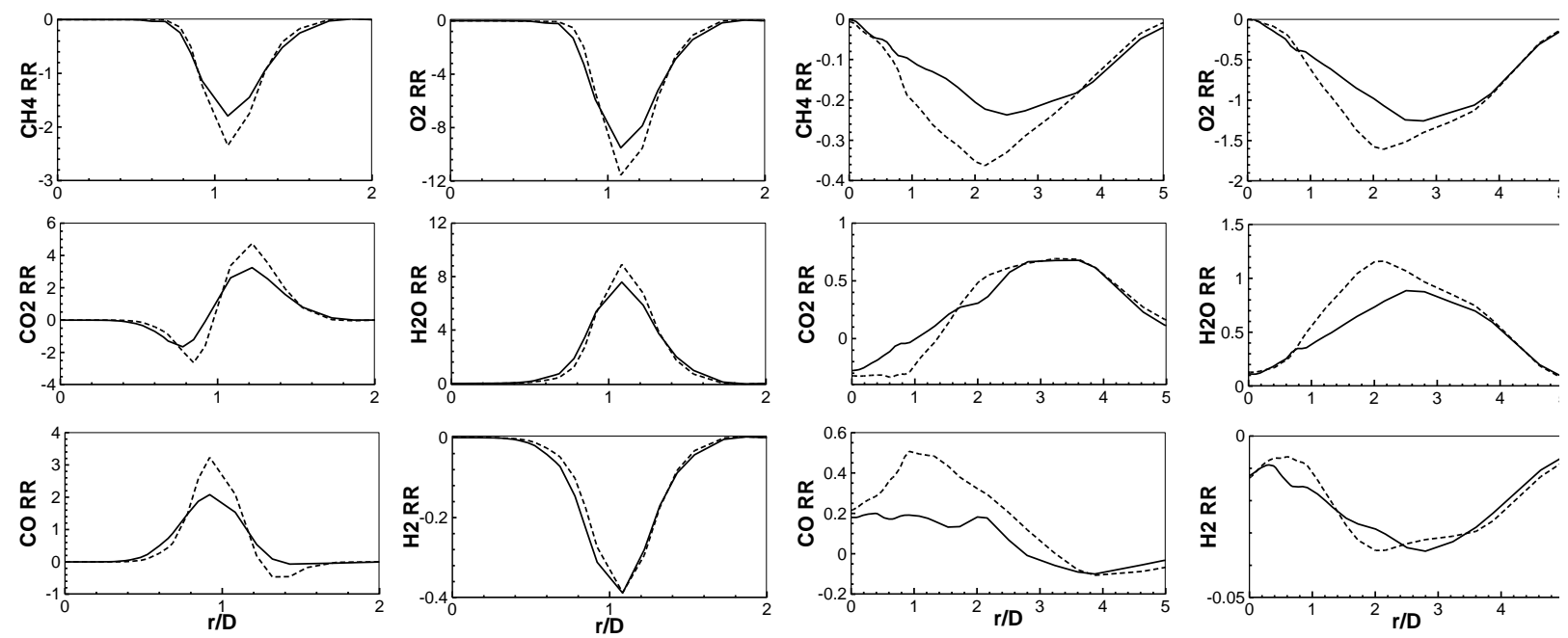

$\mathrm{z} / \mathrm{D}=10$

$\mathrm{z} / \mathrm{D}=40$

Fig. 15 Mole production and consumption of the species at two sections $z / D_{\text {ref }}=10$ and 40 , for DLR-A flame (solid line), and oxygen-enhanced combustion (dashed line)

An important issue arises from that emitted sound is calculated summing source terms up which are distributed over the flame reaction surface. Consequently, the flame area's effect should be taken into account. To do this, source terms are integrated over the simulation domain at each time step. To describe the frequency content and magnitude of the sound source integrations, a Fast Fourier Transform is applied to the time series. The calculation outcomes are shown as HRR and MCPR amplitude as a function of the Strouhal number in Fig. 16. In accordance with Fig. 13 and 14 explanations, the flame becomes more compact by increasing the $\mathrm{O}_{2}$ level in the oxidizer stream. As a consequence, there are two competing effects which influence sound pressure level: increasing HRR and MCPR terms, and decreasing the source terms region due to the flame compactness by OEC. Here it can be seen that how flame surface decrease has mainly affected MCPR source term and thus its contribution in emitted sound pressure level.
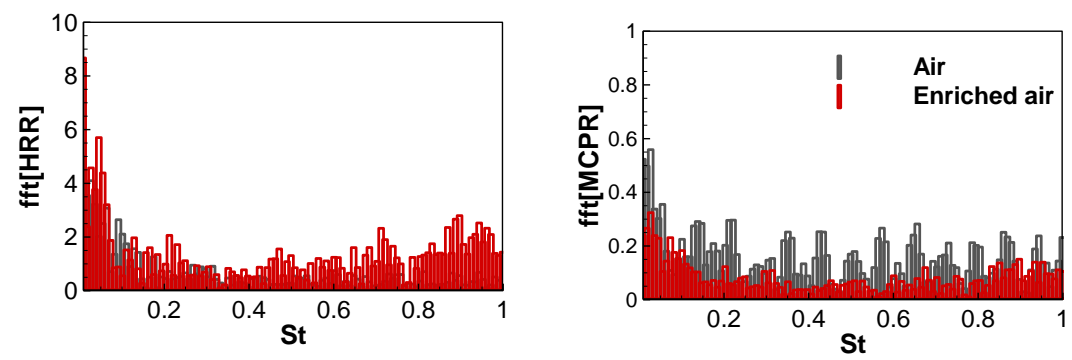
Fig. 16 spectrum of integrated HRR and MPCR over the simulation domain, for DLR-A flame (gray), and oxygen-enhanced combustion (red)

\section{Parametric study}

A parametric study is performed to evaluate oxygen concentration alteration effect on the emitted noise. For this, oxygen enrichment percentage in the air stream has been enhanced up to 10 as well as 20 . The previously discussed high fidelity simulation method is employed to predict the sound pressure level. The results are presented in Fig. 17 for both monopole combustion noise source terms including heat release rate and mole production and consumption. Noise level in Fig. 17(a) is calculated considering heat release rate fluctuations. It can be observed that combustion noise has increased at all frequencies and is predominant in low frequencies. Due to the more strengthen heat release rate and higher rate of its oscillation, noise level maximum increases from $60 \mathrm{~dB}$ for combustion with air to $80 \mathrm{~dB}$ and $110 \mathrm{~dB}$ for combustion with $10 \%$ and $20 \%$ enriched air, respectively. With increasing oxygen concentration, the peak frequency shifts from 0.02 for air toward 0.035 for $10 \%$ and 0.05 for $20 \%$ enriched air. This transfer is caused by increased reaction rate and thus higher levels of chemical reaction and turbulence interaction.

Noise originated from mole production and consumption rate fluctuation is presented in Fig. 17(b). Contribution of this source in total noise emission would be negligible for the reason that this noise level is at least $10 \mathrm{~dB}$ lower than that of heat release rate fluctuations. As was described in section 7, noise level generated in combustion with $10 \%$ enriched air has decreased due to the lower flame volume. However for combustion with $20 \%$ enriched air, increased rate of reactions is adequately enough to compensate flame volume reduction and the resulting noise has increased.

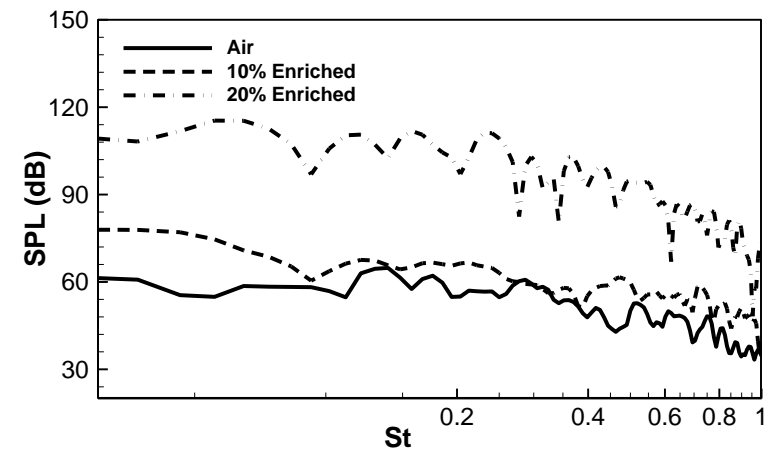

(a)

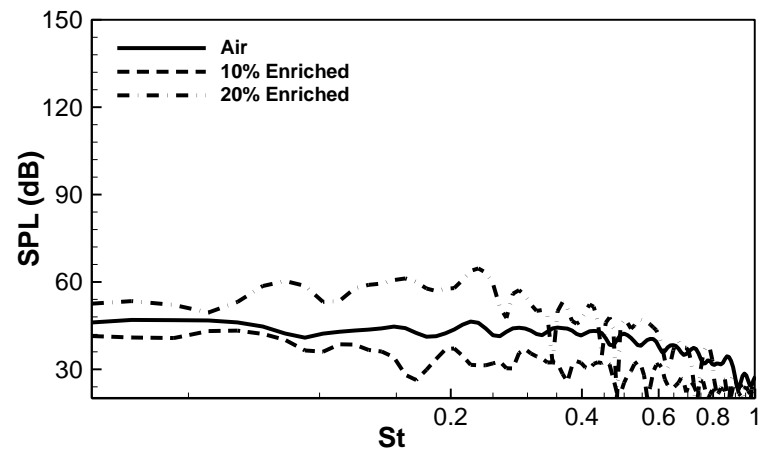

(b) 


\section{Fig. 17 Comparison of (a) heat release rate and (b) mole consumption and production rate fluctuations contribution in emitted combustion noise level for DLR-A flame and OEC with $10 \%$ and $20 \%$ oxygen \\ enhancement}

\section{Conclusion}

Numerical simulation has been carried out to investigate the effect of low-level $\mathrm{O}_{2}$ enhancement of air stream on the flame structure, combustion noise source term generation mechanisms, and farfield emitted noise level in a nonpremixed free flame. For this, numerical simulations were carried out for both cases of DLR-A flame and $10 \%$ enriched air-fuel combustion to compare the results. A Large Eddy Simulation and Partially Stirred Reactor combustion model were employed to simulate the unsteady combustion. Two acoustic source terms contribution due to the heat release rate (HRR) and mole consumption and production rate fluctuations (MCPR) were extracted from the LES results and the Lighthill analogy was utilized to predict the sound pressure level in the farfield. In this simulation, it was shown that enhancing $\mathrm{O}_{2}$ concentration in air stream resulted in higher temperature and reaction rates which lead to an increase about $25 \%$ in the heat release rate and about $20 \%$ increase in the mole consumption and production rate. Total sound pressure level in combustion with air was in good agreement with experimental data and a previous numerical study [43]. Noise spectrum maximum calculated at about $200 \mathrm{~Hz}$ which is consistence with low frequency nature of combustion noise in Meier's measurements [39]. $\mathrm{O}_{2}$ enhancement increased SPL in all frequencies, especially up to $20 \mathrm{~dB}$ in low frequency ranges. In higher frequencies an increase about $10 \mathrm{~dB}$ was observed. Comparison of contributions of two noise source terms showed that mole consumption and production rate did not play a vital role in the emitted noise level. Although magnitude and rate of fluctuation of both noise sources are increased in low-level enriched air combustion, only noise due to the HRR fluctuations increases compared to the combustion with air. Reduction in MCPR noise was investigated and it was concluded that flame compactness which reduces the flame volume, acts as a competitive process to the increased reaction rates and mole consumption and production rate. In case of $\mathrm{HRR}$ source term, heat release rate increment by $\mathrm{O}_{2}$-enhancement overcame the decrease in flame surface and HRR noise level increased. On the contrary, flame volume reduction was the dominant phenomenon and reduced the resultant sound pressure level of MCPR source term about $5 \mathrm{~dB}$ in high and $10 \mathrm{~dB}$ in low frequencies. This phenomenon was not notices in previous studies. A parametric study on $\mathrm{O}_{2}$ concentration in air stream showed that by increasing oxygen concentration, the sound pressure level increases and peak frequency shifts toward higher frequencies. 


\section{8. $\quad$ Funding}

This research did not receive any specific grant from funding agencies in the public, commercial, or not-for-profit sectors.

\section{References}

[1] Schlucknera C, Gabera C, Demuthb M, Forstingera S, Prielera R, Hochenauer C. CFD-model to predict the local and time-dependent scale formation of steels in air- and oxygen enriched combustion atmospheres. Appl Therm Eng 2018;143:822-35. https://doi.org/10.1016/j.applthermaleng.2018.08.010.

[2] Oliveira FAD, Carvalho JA, Sobrinho PM, de Castro A. Analysis of oxy-fuel combustion as an alternative to combustion with air in metal reheating furnaces. Energy 2014;78:290-7. https://doi.org/10.1016/j.energy.2014.10.010.

[3] Wu KK, Chang YC, Chen CH, Chen Y Da. High-efficiency combustion of natural gas with 21-30\% oxygenenriched air. Fuel 2010;89:2455-62. https://doi.org/10.1016/j.fuel.2010.02.002.

[4] Roberto A, Júnior DT, Zimmer L, Schneider PS, Boeira S, Maidana CF. Efficiency of gas turbine assemblies operating under oxygen enhanced combustion ( OEC ). 2nd Oxyfuel Combust. Conf. Oxyfuel Combust. Conf., 2002, p. 3-5.

[5] Ma C, Li B, Chen D, Wenga T, Ma W, Lin F, et al. An investigation of an oxygen-enriched combustion of municipal solid waste on flue gas emission and combustion performance at a $8 \mathrm{MW}$ th waste-to-energy plant. Waste Manag 2019;96:47-56. https://doi.org/10.1016/j.wasman.2019.07.017.

[6] Baukal CE. Oxygen-Enhanced Combustion. 2nd Ed. CRC Press; 2013.

[7] Pillai AL, Kurose R. Combustion noise analysis of a turbulent spray flame using a hybrid DNS / APE-RF approach. Combust Flame 2019;200:168-91. https://doi.org/10.1016/j.combustflame.2018.10.041.

[8] SONG X-R C. Experimental study of combustion noise generated by oxygen-fuel burners. INTER-NOISE NOISE-CON Congr. Conf. Proc., Institute of Noise Control Engineering; 1993, p. 97-102.

[9] Prieler R, Mayr B, Demuth M, Spoljaric D, Hochenauer C. Application of the steady flamelet model on a labscale and an industrial furnace for different oxygen concentrations. Energy 2015;91:451-64. https://doi.org/10.1016/j.energy.2015.08.070.

[10] Maidana CF, Carotenuto A, Schneider PS. Reduction of Fuel Consumption and Emissions of a Gas Turbine by Using of Oxygen-Enriched Combustion. 2nd Oxyfuel Combust Conf 2011:2-5. 
[11] Baskar P, Senthil Kumar AS. Effect of oxygen enrichment on combustion characteristics of a diesel engine. J Eng Sci Technol 2017;12:3023-33. https://doi.org/10.1063/1.2171965.

[12] Pástor M, Kizek J, Jablonský G, Dzurňák R, Varga A, Lukáč L. Impact of oxygen enhanced combustion of natural gas on thermal efficiency of combustion aggregate. MATEC Web Conf 2018;168:07016. https://doi.org/10.1051/matecconf/201816807016.

[13] Pausch K, Herff S, Zhang F, Bockhorn H, Schr W. Noise Sources of Lean Premixed Flames. Flow, Turbul Combust 2019;103:773-796. https://doi.org/10.1007/s10494-019-00032-0.

[14] Liu Y, Dowling AP, Swaminathan N, Dunstan TD. Spatial correlation of heat release rate and sound emission from turbulent premixed flames. Combust $\quad$ Flame 2012;159:2430-40. https://doi.org/10.1016/j.combustflame.2012.03.003.

[15] Xiong C, Jiang Y. Numerical investigation of shear layer effect on sound generation in jet diffusion flame. J Acoust Soc Am 2018;143:1441-1450.

[16] Shoji T. Effects of Flame Structures on Direct Combustion Noise Produced By Lean-Premixed H 2 / Air LowSwirl Jet Flames. AIAA J 2020:1-22. https://doi.org/10.2514/6.2020-0918.

[17] Bagheri G, Ranzi E, Pelucchi M, Parente A, Frassoldati A, Faravelli T. Comprehensive kinetic study of combustion technologies for low environmental impact: MILD and OXY-fuel combustion of methane. Combust Flame 2020;212:142-55. https://doi.org/10.1016/j.combustflame.2019.10.014.

[18] Skeen SA, Yablonsky G, Axelbaum RL. Characteristics of non-premixed oxygen-enhanced combustion: I. The presence of appreciable oxygen at the location of maximum temperature. Combust Flame 2009;156:2145-52. https://doi.org/10.1016/j.combustflame.2009.07.009.

[19] Skeen SA, Yablonsky G, Axelbaum RL. Characteristics of non-premixed oxygen-enhanced combustion : II . Flame structure effects on soot precursor kinetics resulting in soot-free flames. Combust Flame 2010;157:1745-52. https://doi.org/10.1016/j.combustflame.2010.04.013.

[20] Brouzet D. Investigation of Direct Combustion Noise in Turbulent Premixed Jet Flames Using Direct Numerical Simulations. The University of Melbourne, 2020.

[21] Zhang F, Zirwes T, Nawroth H, Habisreuther P, Bockhorn H, Paschereit CO. Combustion-Generated Noise: An Environment-Related Issue for Future Combustion Systems. Energy Technol 2017;5:1045-54. https://doi.org/10.1002/ente.201600526. 
[22] Livebardon T, Moreau S, Gicquel L, Poinsot T, Bouty E. Combining LES of combustion chamber and an actuator disk theory to predict combustion noise in a helicopter engine. Combust Flame 2016;165:272-87. https://doi.org/10.1016/j.combustflame.2015.12.012.

[23] Merk M, Gaudron R, Silva C, Gatti M, Mirat C, Schuller T, et al. Prediction of combustion noise of an enclosed flame by simultaneous identification of noise source and flame dynamics. Proc Combust Inst 2019;37:5263-70.

[24] Férand M, Livebardon T, Moreau S. Numerical Prediction of Far-Field Combustion Noise from Aeronautical Engines Numerical Prediction of Far-Field Combustion Noise from Aeronautical Engines. Acoustics 2019;1:174-98. https://doi.org/10.3390/acoustics1010012.

[25] Poinsot T, Veynante D. Theoretical and numerical combustion. J Chem Inf Model 2013;53:1689-99. https://doi.org/10.1145/1645953.1646237.

[26] Weller HG, Tabor G, Jasak H, Fureby C. A tensorial approach to computational continuum mechanics using object-oriented techniques. Comput Phys 1998;12:620. https://doi.org/10.1063/1.168744.

[27] Sagaut P. Large-Eddy Simulation: state of the art (presentation), 2013.

[28] Turns SR. An Introduction to Combustion: Concepts and Applications. 3rd ed. McGraw-Hill; 2012.

[29] Peters N. Combustion Theory, CEFRC Summer School, Prinston: 2010.

[30] Sabelnikov V, Fureby C. EXTENDED LES-PaSR MODEL FOR SIMULATION OF TURBULENT COMBUSTION. EUCASS Proc. Ser., vol. 4, 2013, p. 539-68. https://doi.org/10.1051/eucass/201304539.

[31] Bibrzycki J, Poinsot T. Reduced chemical kinetic mechanisms for methane combustion in $\mathrm{O}_{2} / \mathrm{N}_{2}$ and $\mathrm{O}_{2} / \mathrm{CO}_{2}$ atmosphere. Work Note ECCOMET WN/CFD/10/17, $\quad$ CERFACS 2010. https://doi.org/10.1016/j.combustflame.2007.10.022.

[32] Crighton DG, Dowling AP, Ffowcs Williams JE, Heckl M, Leppington FG. Modern Methods in Analytical Acoustics. vol. 92. 1992. https://doi.org/10.1121/1.404334.

[33] Dowling AP, Mahmoudi Y. Combustion noise. Proc Combust Inst 2015;35:65-100. https://doi.org/10.1016/j.proci.2014.08.016.

[34] Candel S, Durox D, Ducruix S, Birbaud AL, Noiray N, Schuller T. Flame Dynamics and Combustion Noise: Progress and Challenges. Int J Aeroacoustics 2009;8:1-56.

[35] Delfs PJ. Grundlagen der Aeroakustik ( Basics of Aeroacoustics ). Technische Universität Braunschweig; 
2017.

[36] Swaminathan N, Xu G, Dowling a. P, Balachandran R. Prediction of Sound Emission from Open Turbulent Premixed Flames. 16th AIAA/CEAS Aeroacoustics Conf 2010:1-12. https://doi.org/10.2514/6.2010-3859.

[37] Hirschberg a, Rienstra SW. An introduction to acoustics. Eindhoven University of Technology; 2019.

[38] Swaminathan N, Xu G, Dowling AP, Balachandran R. Heat release rate correlation and combustion noise in premixed flames. vol. 681. 2011. https://doi.org/10.1017/jfm.2011.232.

[39] Meier W. Raman / Rayleigh / LIF Measurements in a Turbulent CH 4 / H 2 / N 2 Jet Diffusion Flame: Experimental Techniques and Turbulence - Chemistry Interaction. Combust Flame 2000;343:326-43.

[40] Versteeg HK., Malalasekera W. An Introduction to Computational Fluid Dynamics. vol. M. 2007. https://doi.org/10.2514/1.22547.

[41] Singh KK, Frankel SH, Gore JP. Study of Spectral Noise Emissions from Standard Turbulent Nonpremixed Flames. AIAA J 2004;42:931-6. https://doi.org/10.2514/1.3424.

[42] Ihme M, Pitsch H. On the generation of direct combustion noise in turbulent non-premixed flames. Int $\mathbf{J}$ Aeroacoustics 2012;11:25-78. https://doi.org/10.1260/1475-472X.11.1.25.

[43] Mühlbauer B, Ewert R, Kornow O, Noll B. Broadband Combustion Noise Simulation of Open Non-Premixed Turbulent Jet Flames. Int J Aeroacoustics 2012;11:1-24. https://doi.org/10.1260/1475-472X.11.1.1.

[44] Bui T, Ihme M, Meinke M, Schroeder W, Pitsch H. Numerical Investigation of Combustion Noise and Sound Source Mechanisms in a Non-Premixed Flame Using LES and APE-RF. 13th AIAA/CEAS Aeroacoustics Conf (28th AIAA Aeroacoustics Conf 2007. https://doi.org/10.2514/6.2007-3406.

[45] Skeen S. Oxygen-Enhanced Combustion: Theory and Applications. Washington University in St. Louis, 2009. https://doi.org/10.7936/K7MC8X35.

[46] Chen R, Axelbaum RL. Scalar dissipation rate at extinction and the effects of oxygen-enriched combustion. Combust Flame 2005;142:62-71. https://doi.org/10.1016/j.combustflame.2005.02.008. 